\title{
Shielding Evaluation of Diagnostic X-Ray Rooms in Khartoum State
}

\author{
Suhaib Alameen ${ }^{1}$, Siddig Khalid ${ }^{2}$, Wadah $\mathrm{Ali}^{3}$ \& Mamdouh Y. Osman ${ }^{2}$ \\ ${ }^{1}$ Sudan University of Science and Technology, College of Medical Radiologic, Khartoum, Sudan \\ ${ }^{2}$ Al Neelain University, Faculty of Science and Technology, Department of Medical Physics, Khartoum, Sudan \\ ${ }^{3}$ College of Allied Health Science, Gulf Medical University, Medical Imaging Department, Ajman, UAE \\ Correspondence: Suhaib Alameen, Sudan University of Science and Technology, College of Medical Radiologic, \\ Science, P.O.Box 1908, Khartoum, Sudan.
}

$\begin{array}{lc}\text { Received: March 11, } 2017 & \text { Accepted: March 31, } 2017 \quad \text { Online Published: May 8, } 2017 \\ \text { doi:10.5539/gjhs.v9n7p161 } & \text { URL: https://doi.org/10.5539/gjhs.v9n7p161 }\end{array}$

\begin{abstract}
The purpose of this study is to evaluate the shielding of some conventional x-ray rooms in Khartoum state. This study is based on the shielding calculations stated in the NCRP report number 49. This is the first time in Sudan to evaluate the shielding of diagnostic $\mathrm{x}$-ray rooms based on this report.

The total number of conventional $x$ - ray rooms included in this study is 9 and the main parameters recorded during the evaluation are the KVp, mAs, and distance from the $\mathrm{x}$-ray source to the measuring points. The dose rate at some selected points both inside and outside each x-ray room have been recorded using two dosimeters.

The result of the evaluation revealed that $75 \%$ of the tested controlled area and $71.4 \%$ of the uncontrolled areas passed the test and do comply with the recommended limiting doses. However, only one room was found to be well shielded for both controlled and uncontrolled areas. The maximum allowed dose rate in controlled and uncontrolled areas was taken equal to $5 \mathrm{mSv} / \mathrm{year} \& 1 \mathrm{mSv} / \mathrm{year}$ respectively and as recommended by the International Atomic Energy Agency (IAEA). Calculations of the required shielding have been made for those areas which have not passed the tests and for lead and concrete.
\end{abstract}

Keywords: shielding, x- ray, NCRP 49, HVL, Barrier

\section{Introduction}

Protective barriers in radiography rooms play an important role in avoiding staff unwanted absorbed dose. In report No.49 the dose limit for has been determined to be 100 and 10 milli-Rontgen (mR) per week, respectively (National Council on Radiation Protection and Measurements, 1976; Archer, 2005), in controlled area for radiation workers and general public in uncontrolled areas. Several remarkable changes have been made in dose limits after NCRP No.49 publication. In report No.116 (1993) the dose limits was reduced considerably for both radiation workers and public (Gray \& Archer, 1994). The proposed design limits reduced NCRP 49 levels by a factor of ten for controlled areas, and by a factor of five for non-controlled areas. Shielding to the dose limits of NCRP 116 and methodology presented in NCRP 49 generated barriers thicker than those currently in use in diagnostic facilities (Gray \& Archer, 1994; Petrantonaki et al., 1999; Simpkin, 1987, 1996). On the other hand, the sufficiency of these barriers to reduce doses to the lower levels have been proven using evidence from the years of film badge records (Gray \& Archer, 1994; Borasi \& Ferretti, 1989; Costa \& Caldas, 2002). This new approach increased the previously calculated thickness of barriers considerably.

$\mathrm{X}$-rays have over the years become an important tool in medical diagnosis and therapy. However, if the $\mathrm{x}$-rays are not shielded such that they only interact with the intended locations, they are potentially hazard to the workers, patients and members of the public (ICRP, 1990; IAEA, 1996).

NCRP 49 presents methodologies to determine protective shielding for diagnostic and therapeutic $x$-ray rooms. It was written more than two decades ago and, in the case of diagnostic shielding, uses data obtained with x-ray technologies that are not in use anymore. Moreover, the NCRP49 formulation and data do not include information regarding mammography, computed tomography and digital radiography room shielding. Other limitations of this report include a lack of information regarding other shielding materials besides lead and concrete, the conservatism of the "add one HVL" rule, (Archer, Thornby, \& Bushong, 1983) questions about limits for film storage, use and occupancy factors, and other design details. 
Based on these arguments, the NCRP and the American Association of Physicists in Medicine AAPM Constituted Task Group 9 with the aim of performing a revision for a new version of NCRP49. Since its creation, members of the Task Group 9 have published several papers (Archer, Fewell, Conway, \& Quinn, 1994; Simpkin, 1996; Suleiman, Conway, Fewell, Slayton, \& Rueter, 1995; Archer, 1997; Dixon R. L., \& Simpkin, n.d.; Dixon, 1994; Dixon \& Simpkin, 1998; Simpkin \& Dixon, 1998; Simpkin, 1995).

Improving data and reviewing methods for shielding calculation for diagnostic rooms.

In 2004, the report No.147 proposed new guidelines for shielding design in radiography rooms. The differences between two reports, No.49 and 147, were discussed in details by some articles (National Council on Radiation Protection and Measurements, 2004). For occupational exposure, NCRP No.116 recommended that all new facilities should be designed to limit annual exposures to a fraction of the $10 \mathrm{mSvy}^{-1}$ (Archer, 1995; Petrantonaki et al., 1999) limit implied by the cumulative dose limit. One-half of this fraction is recommended by report No.147; therefore, the annual effective value for individuals was reduced to $5 \mathrm{mSvy}^{-1}$ in controlled areas. For shielding individuals in controlled area, based on ICRP 60 and NCRP No.116 recommendations, shielding designs shall limit exposure of all individuals in controlled areas to an effective dose that does not exceed $1 \mathrm{mSvy}^{-1}$. Thus, the recommendation of NCRP 147 for uncontrolled area is a shielding design goal (in air kerma) of 0.02 mGy per week (1mGy y). Additionally, report 147 proposes new guidance for occupancy and use factors based on more realistic estimates. Further, the report No.147 uses the survey data of Task Group 13 by Simpkin. In Simpkin survey, workload in various types of diagnostic settings, the weekly average number of patients, the $\mathrm{kVp}$ distribution and the use factors in diagnostic rooms were determined ${ }^{-1}$. In report No.147, for primary barrier shielding calculation, it is recognized that the primary beam is reduced due to attenuation by the patient, the image receptor, and the structures supporting the image receptor (Gray \& Archer, 1994; Simpkin, 1996).

In many radiography departments the shielding calculations had been based on the report (Gray \& Archer, 1994; National Council on Radiation Protection and Measurements, 2004) no.49 of NCRP which uses constant workload for all radiography installation and higher dose limits compared to new protocols. The variation of workload and adapting new dose limits makes it necessary to re-evaluate the primary and secondary shielding thickness periodically. Also, applying the new dose limits recommended by NCRP 116 in recent years has necessitated thicker shielding and higher cost for optimizing old radiography rooms as well as new installations.

\section{Material and Methods}

1. survey meter "Rados " Specifications: - Radiation: Gamma and x-rays, Detection: $50 \mathrm{Kev}-13 \mathrm{MeV}, 0.05 \mu \mathrm{Sv} / \mathrm{h}$ $10 \mathrm{mSv} / \mathrm{h}, 80 \mathrm{Kev}-1.3 \mathrm{MeV}, 10 \mathrm{mSv} / \mathrm{h}-10 \mathrm{~Sv} / \mathrm{h}$, Beta radiation with an external detector.

Measurement range: Dose rate $0.05 \mu \mathrm{Sv} / \mathrm{h}-10 \mathrm{~Sv} / \mathrm{h}$, Dose $0.01 \mu \mathrm{Sv}-10 \mathrm{~Sv}$.

2. survey meter "SMART ION": The smart ion is an advanced microcomputer-based instrument for the measurement of Gamma, Beta and x-ray radiation. Energy range: $\gamma: 18 \mathrm{Kev}-13 \mathrm{MeV}, \beta: 0.2-2.5 \mathrm{MeV}$

3. Water phantom: The water phantom dimensions were length $(25 \mathrm{~cm})$, width $(18 \mathrm{~cm})$ and depth $(10 \mathrm{~cm})$.

The safe use of conventional x-ray machine rooms in diagnostic radiography can be achieved both for workers and public by applying adequate shielding for such rooms. Different methods have been applied to achieve these objectives in which we monitored and calculated the factors that control the thickness of barriers e.g. work lead (W), use factor (U), occupancy factor (T) and source - shielding distance (d) in meter.

By using the above mentioned factors the thickness for the primary and secondary protective barriers have been calculated for all the walls, floor and ceiling of the x-ray rooms. The calculations have been made using the recommendations of the IAEA and the formula stated in the NCRP report no. 49.

\section{For primary}

In order to recognize that the primary protective barrier might be irradiated for only a fraction. $U$, of the total beam $\mathrm{ON}$ - time and that the anticipated occupancy of the point of interest may be a fraction, of the time which the beam is $\mathrm{ON}$ and the barrier protecting the point of interest is irradiated, the value of $\mathrm{W}$ in the denominator of equation $3 \mathrm{~b}$ must be modified by multiplying it by the product, UT. That is

\section{Barrier against scattered radiation:}

$$
B_{u x}=\frac{P\left(d_{p r i}\right)^{2}}{W U T}
$$

The ratio, "a" of the scattered to incident exposure is a function of energy and scattering angle. Since the exposure rate $X_{u}$ of scattered radiation measured at one meter from a scattered $1 \mathrm{~m}$ from the source is proportional to F. For 
$\mathrm{x}$-ray generated at voltage of $500 \mathrm{Kv}$ and below, it is usually assumed that the barrier penetrating capability of scattered phantom is the same as that of the useful beam.

$$
K_{u x}=\frac{P}{a W T}\left(d_{s c a}\right)^{2} \cdot\left(d_{\mathrm{sec}}\right)^{2} \frac{400}{F}
$$

Thus the barrier thickness required to reduce the exposure to $\mathrm{P}$ is the one that corresponds to the value $\mathrm{K}_{\mathrm{ux}}$ and the pertinent attenuation curve.

$\mathrm{K}_{\mathrm{ux}}$ : The number of roentgens per milliampere in minute in week for useful beam.

\section{Barrier against leakage radiation:}

For a diagnostic type protection, tube hosing, the leakage 1, is equal 0.1 roentgen in an hour at one meter from the source

$$
B_{l X}=\frac{P\left(d_{\text {sec }}\right)^{2}(600 I)}{W T}
$$

The thickness of barrier, $\mathrm{S}_{1}$ to protect from leakage radiation at the point of interest can be computed as follows suing the value of $B_{l x}$, the value of $\mathrm{N}$ or $\mathrm{n}$ is read on the appropriate abscissa. The leakage barrier thickness $\mathrm{S}_{1}$ is computed.

Where, numerical values of HVL or TVL.

$$
\mathrm{S}_{1}=\mathrm{N}(\mathrm{HVL}) \text { or } \mathrm{n}(\mathrm{TVL})
$$

Experimental procedure: The workload for different 9 rooms conventional $x$-ray rooms were calculated in each room the exposures factor $(\mathrm{Kv}, \mathrm{mA}$, time and distance) of each $\mathrm{x}$-ray examination in each $\mathrm{x}$-ray room were recorded and for a period of one week Also the dose rate in controlled and uncontrolled areas were measured using a survey meter and under the use of maximum used exposure factors of the x-ray machine.

\section{Results}

Table 1. Dose Rate Measurements Using Rados survey meter

\begin{tabular}{lll}
\hline Hospitals & Controlled Area (Avg $\boldsymbol{\mu S v} / \mathbf{h})$ & Un Controlled Area $($ Avg $\mu \mathbf{S v} / \mathbf{h})$ \\
\hline A & $0.79 \pm 0.057$ & $0.89 \pm 0.051$ \\
B & 0 & $1.71 \pm 0.10$ \\
C & 0 & 0 \\
D & $25.56 \pm 2.8$ & $8.46 \pm 0.95$ \\
E & $8.85 \pm 1.12$ & $0.74 \pm 0.05$ \\
F & 0 & $0.43 \pm 0.09$ \\
G & $5.79 \pm 0.16$ & 0 \\
H & $15.47 \pm 4.68$ & 0 \\
I & $1.81 \pm 0$ & 0 \\
\hline
\end{tabular}

Table 2. Dose Rate Measurements Using SMART survey meter

\begin{tabular}{lll}
\hline Hospitals & Controlled Area $(\operatorname{Avg} \boldsymbol{\mu S v} / \mathbf{h})$ & Un Controlled Area $(\operatorname{Avg} \boldsymbol{\mu S v} / \mathbf{h})$ \\
\hline A & $2.50 \pm 0.35$ & $2.95 \pm 0.66$ \\
B & $0.31 \pm 0.00$ & $0.34 \pm 0.63$ \\
C & 0 & 0 \\
D & $29.04 \pm 5.02$ & $7.97 \pm 1.14$ \\
E & $8.11 \pm 1.35$ & $0.34 \pm 0.06$ \\
F & 0 & $0.65 \pm 0.06$ \\
G & $5.06 \pm 0.62$ & 0 \\
H & $20.55 \pm 6.92$ & 0 \\
$\mathbf{I}$ & $1.28 \pm 0.12$ & 0 \\
\hline
\end{tabular}


Table 3. Summary of the Results in Controlled Areas

\begin{tabular}{lll}
\hline Hospital & Number of Readings & Accepted Results \% \\
\hline A & 2 & 100 \\
B & 2 & 100 \\
C & 2 & 100 \\
D & 3 & 33.3 \\
E & 2 & 50 \\
F & 4 & 100 \\
G & 3 & 66.7 \\
H & 1 & 0 \\
I & 1 & 100 \\
Overall Result & $\mathbf{2 5}$ & $\mathbf{7 5}$ \\
\hline
\end{tabular}

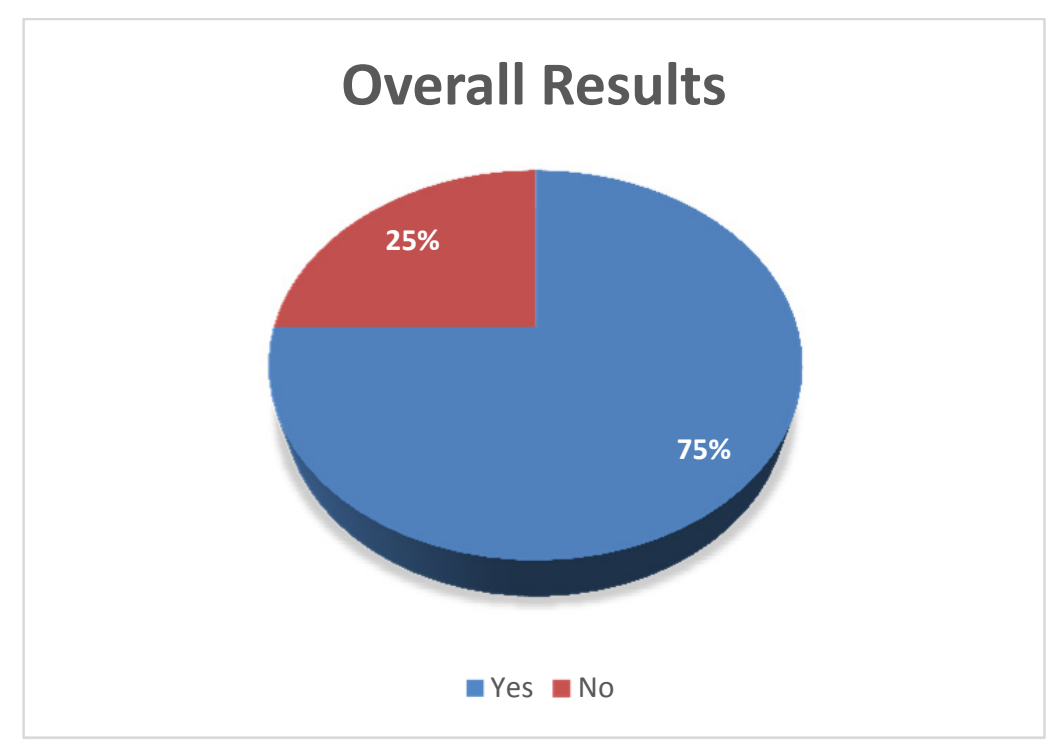

Figure 1. Summary of the results of control area

Table 4. Summary of the results in uncontrolled areas

\begin{tabular}{lll}
\hline Hospital & Number of readings & Accepted Results \% \\
\hline A & 3 & 66.7 \\
B & 3 & 33.3 \\
C & 4 & 100.0 \\
D & 3 & 66.7 \\
E & 4 & 50.0 \\
F & 1 & 0.0 \\
G & 3 & 100.0 \\
H & 4 & 100.0 \\
I & 3 & 66.7 \\
\hline Overall Result & $\mathbf{2 8}$ & $\mathbf{7 1 . 4}$ \\
\hline
\end{tabular}




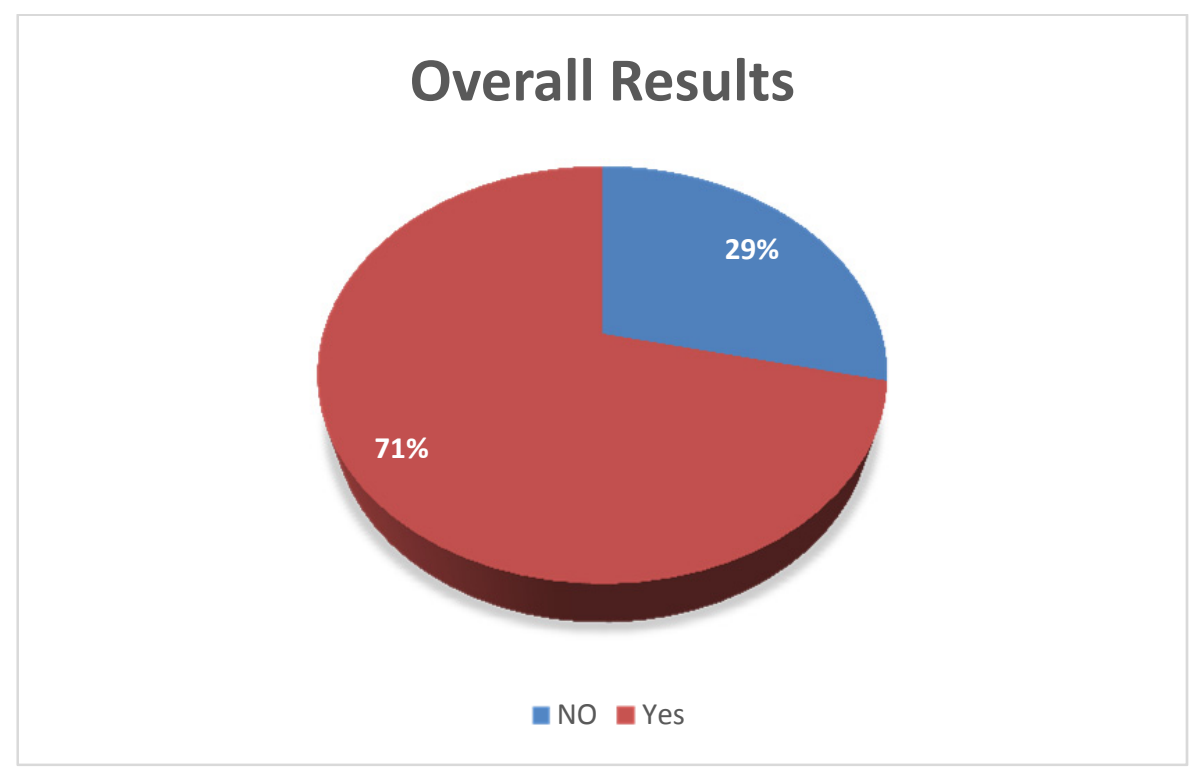

Figure 2. Summary of the results of uncontrolled area

Table 5. Show the work load for each $\mathrm{x}$-ray machines were calculated as the average of the actual mA-min applied in a week for each x-ray machine

\begin{tabular}{llll}
\hline Hospital & $\begin{array}{l}\text { Workload } \\
(\mathrm{mAmin} / \text { week })\end{array}$ & $\begin{array}{l}\text { Distance to control room } \\
(\mathrm{m})\end{array}$ & $\begin{array}{l}\text { Area } \\
\left(\mathrm{m}^{2}\right)\end{array}$ \\
\hline $\mathrm{A}$ & 215.90 & 1.25 & 32.67 \\
$\mathrm{~B}$ & 74.17 & 2.20 & 24.08 \\
$\mathrm{C}$ & 103.23 & 2.80 & 25.38 \\
$\mathrm{D}$ & 42.18 & 2.50 & 15.07 \\
$\mathrm{E}$ & 122.32 & 2.70 & 33.60 \\
$\mathrm{~F}$ & 130.00 & 2.40 & 23.00 \\
$\mathrm{G}$ & 23.80 & 2.35 & 42.18 \\
$\mathrm{H}$ & 125.70 & 1.50 & 15.40 \\
$\mathrm{I}$ & 115.41 & 2.65 & 28.37 \\
\hline
\end{tabular}

\section{Discussion}

This study has been conducted the conventional x-ray rooms in Khartoum state and covered 9 rooms.

The main objective was to evaluate the shielding of such x-ray rooms, as well as to calculate the thickness of the required shielding for each room. The shielding calculations were performed in according to the NCRP report No. 49. The accepted dose rate in the surrounded areas of each $\mathrm{x}$-ray room were based on the recommendations of the IAEA, $5 \mathrm{mSv}$ per year $(0.1 \mathrm{mSv} /$ week $)$ for controlled areas and, $1 \mathrm{mSv}$ per year $(0.02 \mathrm{mSv} /$ week $)$ for uncontrolled areas. Based on these values the maximum permissible dose rate per hours were calculated to be equal to $2.1 \mu \mathrm{Sv} / \mathrm{h}$ and $0.42 \mu \mathrm{Sv} / \mathrm{h}$ for controlled and non controlled area respectively.

Also values of the use and occupancy factors mentioned in the above by NCRP report were adopted. The work load for each x-ray machines were calculated as the average of the actual mA-min applied in a week for each $\mathrm{x}$-ray machine Table 5 .

For better accuracy of the measured dose rate two different dosimeters were used in this study. Also for the sake of increasing the precision of measurements, the averaged of three readings were taken at each point of measurements. The average number of measurements points per $\mathrm{x}$-ray room was five. The number of readings for each $\mathrm{x}$-ray room depends on the room design and location. The monitored Areas were classified into controlled and uncontrolled according to criteria mentioned in relevant international standards especially the Basic Safety Standard No. 115. 
On taking the measurements of the dose rate, a water phantom was used to represent the patient and the maximum usable exposure factors were set on each $\mathrm{x}$-ray machine.

The maximum discrepancy between the readings of the two dosimeters was $14 \%$ which was recorded at a point where the dose rate was the highest ( $203 \& 224 \mu \mathrm{Sv} / \mathrm{h}$ for rados \& smart respectively). The results showed that five $\mathrm{x}$-rooms were found to meet the standard criteria with respect to controlled areas that represents $75 \%$ of the total number of tested $\mathrm{x}$-ray rooms and three for uncontrolled areas i.e. $71.4 \%$. However, the overall result of all checked points (48) showed that the shielding of only one x-ray room (i.e. $11.1 \%$ of the total number) did comply with the standards both for controlled and uncontrolled areas. However It is worth mentioning that if the calculations were based on the old recommended values of $10 \mu \mathrm{Sv} / \mathrm{h}$ (equivalent to $20 \mathrm{mSv}$ per year) for controlled areas the percentage of compliance will remains the same i.e. $75 \%$.

\section{Conclusion}

From the above mentioned results and discussion we can conclude that the majority of the tested $\mathrm{x}$-ray rooms (about $89 \%$ ) do not comply with the international recommendations as far as the shielding thickness is concerned. such results illustrated the shortage of qualified staff for proper room design and the absence of the supervision of the regulatory authority on the establishment of such x-ray room. Also as a consequence of the lack of the proper shielding thickness especially to the uncontrolled areas, public are exposed to substantial radiation doses unnecessarily which would increase the risk of inducing stochastic effects particularly among the high risk category of the public e.g. children and pregnant women.

Also, it was quite obvious that there a nearly complete absence of a program of radiation area monitoring which supposed to be done at the time of commissioning of the x-ray department and after any major maintenance or repair to the x-ray machines or any major change in room design or if the work load of the machine increased.

The major recommendations that can be concluded form this study are Constructions of a new x-ray department should be under the supervision of an expert in radiation protection and in compliance with the current international and national regulations so as to offer adequate level of protection for workers and public with a minimum cost. and Each $\mathrm{x}$-ray department should appoint a radiation protection officer so as to establish a radiation protection program which include a routine program for area monitoring which in turn can help in detecting any increase in the radiation levels in any areas near the x-ray rooms.

\section{Competing Interests Statement}

The authors declare that there is no conflict of interests regarding the publication of this paper.

\section{References}

Archer, B. R. (1997). Diagnostic x-ray shielding design — new data and con- cepts. In D. Frey and P. Spraws (Eds.), The Expanding Role in Medical Physics in Diagnostic Imaging, Proceedings of the 1997 AAPM Summer School. Madison, WI: Advanced Medical Publishing.

Archer, B. R. (2005) Recent history of the shielding of medical X-ray imaging facilities. Health Physm, 88, 579-586. https://doi.org/10.1097/01.HP.0000158736.59917.93

Archer, B. R., Fewell, T. R., Conway, B. J., \& Quinn, P. W. (1994). Attenuation properties of diagnostic X-ray shielding materials. Med. Phys., 21, 1499-1507. PMid:7838062 https://doi.org/10.1118/1.597408

Archer, B. R., Thornby, J. I., \& Bushong, S. C. (1983). Diagnostic x-ray shielding design based on an empirical model of photon attenuation. Health Phys, 44, 507-517. PMid:6853171. https://doi.org/10.1097/00004032-198305000-00005

Borasi, G., \& Ferretti, P. P. (1989). Some remarks on secondary protective barrier calculation for radiographic installations: NCRP Report No. 49 revisited. Health Phys, 57, 1025-1033. PMid:2584019

Costa, P. R., \& Caldas, L. V. (2002). Evaluation of protective shielding thickness for diagnostic radiology rooms: theory.

Dixon R. L., \& Simpkin, D. J. (n.d.). New concepts for radiation shielding of medical diagnostic $x$-ray facilities.

Dixon, R. (1994). On the primary barrier in diagnostic x-ray shielding. PMid:7891641. Med. Phys., 21, 1785-1793. https://doi.org/10.1118/1.597217

Dixon, R. L., \& Simpkin, D. J. (1998). Primary shielding barriers for diagnostic x-ray facilities: A new model. Health Phys., 74, 181-189. PMid:9450588. https://doi.org/10.1097/00004032-199802000-00005

Gray, J. E., \& Archer, B. R. (1994). NCRP and AAPM revising NCRP 49. Health Phys, 67, 297. PMid:8056600 
IAEA. (1996). International Basic safety Standards for Radiation Protection against Ionizing radiation and for the Safety of radiation sources. IAEA Safety Series, 115.

ICRP. (1990). Recommendations of the International Commission on Radiological Protection.

National Council on Radiation Protection and Measurements. (1976). Structural shielding design and evaluation for medical use of $x$ rays and gamma rays of energies up to $10 \mathrm{MeV}$. NCRP Report 49. Bethesda MD, NCRP. Ref Type: Report.

National Council on Radiation Protection and Measurements. (2004). Structural shielding design for medical X.ray imaging facilities. NCRP Report No.147. Bethesda MD, NCRP. Ref Type: Report.

Petrantonaki, M., Kappas, C., Efstathopoulos, E. P. et al. (1999). Calculating shielding requirements in diagnostic X-ray departments. Br J Radiol, 72, 179-185. PMid:10365070. https://doi.org/10.1259/bjr.72.854.10365070

Simpkin, D. (1996). Evaluation of NCRP Report No. 49 assumptions on workloads and use factors in diagnostic radiology facilities. Med. Phys., 23, 577-584. PMid:8860905. https://doi.org/10.1118/1.597813

Simpkin, D. J. (1987). A general solution to the shielding of medical $\mathrm{x}$ and gamma rays by the N Report No. 49 methods. Health Phys, 52, 431-436. PMid:3570785. https://doi.org/10.1097/00004032-198704000-00003

Simpkin, D. J. (1995). Transmission data for shielding diagnostic x-ray facilities. Health Phys., 68, 704-709. PMid:7730068. https://doi.org/10.1097/00004032-199505000-00011

Simpkin, D. J. (1996). Evaluation of NCRP Report No. 49 assumptions on workloads and use factors in diagnostic.

Simpkin, D. J., \& Dixon, R. L. (1998). Secondary shielding barriers for diagnostic x-ray facilities: Scatter and leakage revisited. Health Phys., 74, 350-365. PMid:9482601. https://doi.org/10.1097/00004032-199803000-00008

Suleiman, O. H., Conway, B. J., Fewell, T. R., Slayton, R. J., \& Rueter, F. G. (1995). Radiation protection requirements for medical x-ray film. Med. Phys., 22, 1691-1693. PMid:8551996. https://doi.org/10.1118/1.597629

\section{Copyrights}

Copyright for this article is retained by the author(s), with first publication rights granted to the journal.

This is an open-access article distributed under the terms and conditions of the Creative Commons Attribution license (http://creativecommons.org/licenses/by/4.0/). 